\title{
Influence of Pre-deformation on Aging Precipitation Behavior of Three Al-Cu-Li Alloys
}

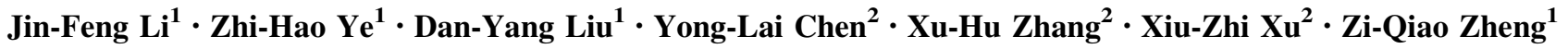

Received: 25 May 2016/Revised: 10 July 2016/Published online: 28 November 2016

(C) The Chinese Society for Metals and Springer-Verlag Berlin Heidelberg 2016

\begin{abstract}
The influence of pre-deformation on aging precipitates of three near peak-aged Al-Cu-Li alloys, 1460 alloy with a low $\mathrm{Cu} / \mathrm{Li}$ ratio (1.46), 2050 alloy with a high $\mathrm{Cu} / \mathrm{Li}$ ratio (4.51) and $2 \mathrm{~A} 96$ alloy with a medium $\mathrm{Cu} / \mathrm{Li}$ ratio (2.97), was investigated. The strength of the aged alloys is enhanced by the pre-deformation. The effectiveness of pre-deformation on precipitates is dependent on the alloy's composition. With increasing the pre-deformation, the population density of T1 $\left(\mathrm{Al}_{2} \mathrm{CuLi}\right)$ precipitates increases in all three $\mathrm{Al}-\mathrm{Cu}-\mathrm{Li}$ alloys and their diameter decreases in 2050 and $2 \mathrm{~A} 96$ alloys, and the greatest effectiveness is observed in $2 \mathrm{~A} 96$ alloy. The pre-deformation also increases the population density of $\theta^{\prime}\left(\mathrm{Al}_{2} \mathrm{Cu}\right)$ precipitates and decreases their diameter in 2050 and 2A96 Al-Li alloys, but the effectiveness is smaller compared to that on $\mathrm{T} 1$ precipitates. In 1460 alloy subjected to two-step aging at $130{ }^{\circ} \mathrm{C}$ for $20 \mathrm{~h}$ followed by $160{ }^{\circ} \mathrm{C}$ for $12 \mathrm{~h}$, the main precipitates are $\delta^{\prime}\left(\mathrm{Al}_{3} \mathrm{Li}\right)$. At $2 \%-6 \%$ pre-deformation, GP-I zones form and pre-deformation displays little influence. Eight percentage pre-deformation promotes $\theta^{\prime \prime} / \theta^{\prime}$ precipitation and increases their population density.
\end{abstract}

KEY WORDS: Al-Li alloy; Pre-deformation; Aging; Precipitates

\section{Introduction}

$\mathrm{Al}-\mathrm{Cu}-\mathrm{Li}$ alloys were considered as the most attractive alloys in the aircraft and aerospace industries because of their desirable properties, such as low density, high-specific strength and elastic modulus, good corrosion resistance, excellent cryogenic properties, low fatigue crack growth rate, and so on $[1,2]$. In fact, the third generation Licontaining Al alloys, such as 2195, 2050, 2099, 2196 and

Available online at http://link.springer.com/journal/40195

Jin-Feng Li

lijinfeng@csu.edu.cn

1 School of Materials Science and Engineering, Central South University, Changsha 410083, China

2 Aerospace Research Institute of Materials and Processing Technology, Beijing 100076, China
2197 alloys were successfully used and performed excellently in aircraft and aerospace structures.

To improve the particular performance of $\mathrm{Al}$ alloys, it is important to select a suitable heat treatment process. For example, T73 and T74 tempers were developed to improve corrosion resistance of 7XXX series Al alloys [3-5]. T77 temper was invented to enhance corrosion resistance with maintained high strength for 7XXX series Al alloys [6]. To ameliorate strength, toughness and ductility, secondary aging was also proposed [7]. For Al-Cu alloys, the most important temper is $\mathrm{T} 8$ aging, which includes artificial aging following pre-deformation after solution treatment. In $\mathrm{Al}-$ $\mathrm{Cu}$ alloys with main precipitates of $\theta^{\prime}\left(\mathrm{Al}_{2} \mathrm{Cu}\right)$, it was well known that their precipitation was accelerated by the plastic deformation prior to artificial aging. The plastic deformation introduces dislocations to the matrix, which act as nucleation sites of $\theta^{\prime}$ precipitates and therefore accelerate the nucleation rate during artificial aging process $[8,9]$.

In $\mathrm{Al}-\mathrm{Cu}-\mathrm{Li}$ alloys, the main strengthening precipitates include $\mathrm{T} 1\left(\mathrm{Al}_{2} \mathrm{CuLi}\right), \theta^{\prime}$ and $\delta^{\prime}\left(\mathrm{Al}_{3} \mathrm{Li}\right)$. The precipitate 
type and fraction are dependent on the alloy's composition, mainly $\mathrm{Cu}$ and $\mathrm{Li}$ concentrations and their ratio. Plastic deformation prior to artificial aging in $\mathrm{Al}-\mathrm{Cu}-\mathrm{Li}$ alloys has been found to enhance the strength, ductility and aging kinetics over non-deformed alloy [10, 11]. Most references contributed the strength enhancement to the refinement of $\mathrm{T} 1$ precipitates caused by plastic deformation prior to artificial aging. The plastic deformation introduces dislocations into the matrix, which act as preferential matrix nucleation sites of strengthening precipitate T1 [12-18]. Increasing the amount of introduced plastic deformation leads to a greater number of matrix dislocations, and therefore increases the population density of $\mathrm{T} 1$ precipitates and decreases their size $[19,20]$. However, for $\theta^{\prime}$ precipitates in $\mathrm{Al}-\mathrm{Cu}-\mathrm{Li}$ alloys, it was reported in some references that the plastic deformation prior to artificial aging deterred their precipitation, and lowered their population (number) density and volume fraction [21]. No references reported that the pre-deformation affected the precipitation of $\delta^{\prime}$ phases. However, augmented T1 volume fraction caused by plastic deformation has been shown to affect $\delta^{\prime}$ precipitation due to limiting the available Li atoms for further nucleation and growth [13].

Because the main type of precipitates as well as their total and individual volume fraction in $\mathrm{Al}-\mathrm{Cu}-\mathrm{Li}$ alloys depends on $\mathrm{Cu}$ and $\mathrm{Li}$ concentrations and $\mathrm{Cu} / \mathrm{Li}$ ratio, the effect of predeformation on the precipitation should be associated with the $\mathrm{Cu} / \mathrm{Li}$ ratio. In addition, the mechanical properties of $\mathrm{Al}-\mathrm{Cu}-$ $\mathrm{Li}$ alloys are attributed to different type, fraction and distribution of distinct precipitates. According to theses two factors, the influence of pre-deformation on aging precipitation of $\mathrm{Al}-$ $\mathrm{Cu}-\mathrm{Li}$ alloys with different $\mathrm{Cu} / \mathrm{Li}$ ratio is important, which helps to select an appropriate pre-deformation during T8 aging. Based on these concerns, the precipitates as well as strength of three $\mathrm{Al}-\mathrm{Cu}-\mathrm{Li}$ alloys aged after different predeformation were investigated in this work, and the three $\mathrm{Al}-$ $\mathrm{Cu}-\mathrm{Li}$ alloys possessed different $\mathrm{Cu} / \mathrm{Li}$ ratio.

\section{Experimental Procedures}

Three $\mathrm{Al}-\mathrm{Cu}-\mathrm{Li}$ alloys with different $\mathrm{Cu}$ and $\mathrm{Li}$ concentrations were prepared. Their chemical compositions are shown in Table 1. Among them, 2A96 alloy is a novel super-high-strength $\mathrm{Al}-\mathrm{Cu}-\mathrm{Li}$ alloy designed by our group.
The Al-Cu-Li alloy ingots were rolled to sheets with $2 \mathrm{~mm}$ in thickness through hot rolling and cold rolling process. The sheets were then subjected to a simple T8 aging treatment after solid solution treatment and quenching in water. The $\mathrm{T} 8$ aging treatment was artificial aging after different pre-deformation through cold rolling. For different alloy, the $\mathrm{T} 8$ aging parameter is shown in Table 2.

Tensile specimens with a parallel section gauged $30 \mathrm{~mm}$ in length and $8 \mathrm{~mm}$ in width were cut from the T8-aged sheets along the rolling direction, according to the National Standard GB/T228.1-2010. Tensile tests were carried out in an MTS testing machine (MTS858 Mini Bionix II, USA) with a tensile rate of $2 \mathrm{~mm} / \mathrm{min}$. The microstructure was observed by transmission electron microscopy (TEM, Tecnai $G^{2} 20$ ). The TEM samples were prepared by a twinjet electro-polishing device in a solution containing $75 \%$ methanol and 25\% nitric acid (volume fraction) from -40 to $-20{ }^{\circ} \mathrm{C}$ with a voltage of $15-30 \mathrm{~V}$ and a current of 70-95 mA.

\section{Results}

\subsection{Mechanical Property Dependence on Pre-deformation}

As the introduction of pre-deformation, the aging response of 2A96 alloy is highly accelerated. For the pre-deformation-free aging at $160{ }^{\circ} \mathrm{C}$, the peak-aging time is up to beyond $100 \mathrm{~h}$. However, as $3 \%-12.5 \%$ pre-deformation is introduced, the peak-aging time is advanced to $15-20 \mathrm{~h}$. Table 3 shows the tensile properties of 2A96 alloy with pre-deformation-free aging for different time and aging for $20 \mathrm{~h}$ (peak-aging) after 3\%-12.5\% pre-deformation. It is shown that the strength of the $2 \mathrm{~A} 96$ alloy aged for $20 \mathrm{~h}$ is

Table 2 T8 aging for different Al-Cu-Li alloy

\begin{tabular}{lll}
\hline Alloy & Pre-deformation (\%) & Aging temp./time \\
\hline 1460 & $2,4,6,8$ & $130{ }^{\circ} \mathrm{C} / 20 \mathrm{~h}+160{ }^{\circ} \mathrm{C} / 12 \mathrm{~h}$ \\
2050 & $2,5,8,10$ & $155^{\circ} \mathrm{C} / 32 \mathrm{~h}$ \\
$2 \mathrm{~A} 96$ & 0 & $160{ }^{\circ} \mathrm{C} / 20 \mathrm{~h}, 78 \mathrm{~h}, 120 \mathrm{~h}$ \\
& $3,6,8,12.5$ & $160{ }^{\circ} \mathrm{C} / 20 \mathrm{~h}$ \\
\hline
\end{tabular}

Table 1 Chemical compositions of the experimental Al-Cu-Li alloys (mass fraction, \%)

\begin{tabular}{lllllllllll}
\hline Alloy & $\mathrm{Cu}$ & $\mathrm{Li}$ & $\mathrm{Mg}$ & $\mathrm{Ag}$ & $\mathrm{Zn}$ & $\mathrm{Mn}$ & $\mathrm{Zr}$ & $\mathrm{Ce}$ & $\mathrm{Al}$ & $\mathrm{Cu} / \mathrm{Li} \mathrm{ratio}$ \\
\hline 1460 & 3.12 & 2.14 & - & - & - & - & 0.11 & 0.05 & Bal. & 1.46 (low) \\
2050 & 3.56 & 0.79 & 0.4 & 0.4 & - & 0.3 & 0.11 & - & Bal. & 4.51 (high) \\
$2 \mathrm{~A} 96$ & 3.81 & 1.28 & 0.39 & 0.4 & 0.4 & 0.3 & 0.12 & - & Bal. & 2.97 (medium) \\
\hline
\end{tabular}


Table 3 Tensile properties of 2A96 alloy aged after different pre-deformation

\begin{tabular}{llllr}
\hline Pre-deformation & Aging temp./time & Tensile strength (MPa) & Yield strength (MPa) & Elongation (\%) \\
\hline 0 & $160^{\circ} \mathrm{C} / 20 \mathrm{~h}$ & 500 & 356 & 53 \\
& $160^{\circ} \mathrm{C} / 78 \mathrm{~h}$ & 589 & 565 & 7.2 \\
& $160^{\circ} \mathrm{C} / 120 \mathrm{~h}$ & 616 & 551 & 7.7 \\
$3 \%$ & $160^{\circ} \mathrm{C} / 20 \mathrm{~h}$ & 600 & 578 & 9.7 \\
$6 \%$ & $160^{\circ} \mathrm{C} / 20 \mathrm{~h}$ & 610 & 585 & 12.7 \\
$8 \%$ & $160^{\circ} \mathrm{C} / 20 \mathrm{~h}$ & 616 & 584 & 9.9 \\
$12.5 \%$ & $160^{\circ} \mathrm{C} / 20 \mathrm{~h}$ & 610 & & 9.6 \\
\hline
\end{tabular}

greatly enhanced by the pre-deformation, but as pre-deformation is higher than $6 \%$, and there is only a very small or even no further strength enhancement.

Tables 4 and 5 show the tensile properties of the 1460 and 2050 alloys aged after different pre-deformation. The tensile property variation with the pre-deformation is different for different alloy. For the 1460 alloy, the strength is sequentially enhanced as the pre-deformation is increased from $2 \%$ to $8 \%$. However, it is different for 2050 alloy. For the 2050 alloy, as the pre-deformation is increased from $2 \%$ to $5 \%$, and the tensile strength is greatly increased from $448 \mathrm{MPa}$ to $518 \mathrm{MPa}$; the enhancement is up to about $70 \mathrm{MPa}$. As the pre-deformation is further increased to $8 \%$ or even $10 \%$, although the tensile strength is further enhanced, the enhancement value is much smaller.

\subsection{Microstructural Variation with Pre-deformation}

\subsubsection{A96 Alloy}

Figure 1 shows SAED (selected area electron diffraction) patterns taken along the $[112]_{\mathrm{Al}}$ and $[100]_{\mathrm{Al}}$ zone axes and centered dark field (DF) TEM images of near peak-aged aged 2A96 alloy with different pre-deformations. By comparing these recorded SAED patterns to those from corresponding zone axis in references [22-24], it is found that in the alloy after pre-deformation-free aging for $78 \mathrm{~h}$, and there exist sharp spots of $\mathrm{T} 1$ and weak streaks of $\mathrm{S}^{\prime}$ $\left(\mathrm{Al}_{2} \mathrm{CuMg}\right)$ in the $[112]_{\mathrm{Al}}$ SAED pattern. Considerable T1 precipitates with a small number of $S^{\prime}$ precipitates are observed in the DF image along the $\langle 112\rangle_{\mathrm{Al}}$ direction (Fig. 1a). Meanwhile, obvious $\theta^{\prime}$ spots appear in the $[100]_{\mathrm{A} 1}$ SAED pattern. Accordingly, considerable $\theta^{\prime}$ precipitates are observed in the DF image along the $<100>_{\text {Al }}$ direction (Fig. 1b). As 3\% pre-deformation is applied, the age-strengthening response is greatly accelerated (Table 3). The population density of $\mathrm{T} 1$ precipitates is increased with a great reduction in diameter, and $S^{\prime}$ precipitates disappear (Fig. 1c). The spots of $\theta^{\prime}$ precipitates still exist in the $[100]_{\mathrm{Al}}$ SAED pattern, but their intensity is a little decreased, and $\theta^{\prime}$ precipitates with smaller size are observed in the DF image along the $<100\rangle_{\mathrm{Al}}$ direction (Fig. 1d).

As the pre-deformation is further increased to $8 \%$, more dense $\mathrm{T} 1$ precipitates with much smaller size are observed

Table 4 Tensile properties of 1460 alloy aged after different pre-deformation

\begin{tabular}{llll}
\hline Pre-deformation (\%) & Tensile strength (MPa) & Yield strength (MPa) & Elongation (\%) \\
\hline 2 & 577 & 463 & 4.8 \\
4 & 580 & 475 & 6.5 \\
6 & 596 & 510 & 6.9 \\
8 & 610 & 537 & 6.6 \\
\hline
\end{tabular}

Table 5 Tensile properties of 2050 alloy aged after different pre-deformation

\begin{tabular}{llll}
\hline Pre-deformation $(\%)$ & Tensile strength $(\mathrm{MPa})$ & Yield strength (MPa) & Elongation $(\%)$ \\
\hline 2 & 448 & 341 & 13.9 \\
5 & 518 & 479 & 11.2 \\
8 & 538 & 479 & 10.7 \\
10 & 543 & 489 & 10.9 \\
\hline
\end{tabular}



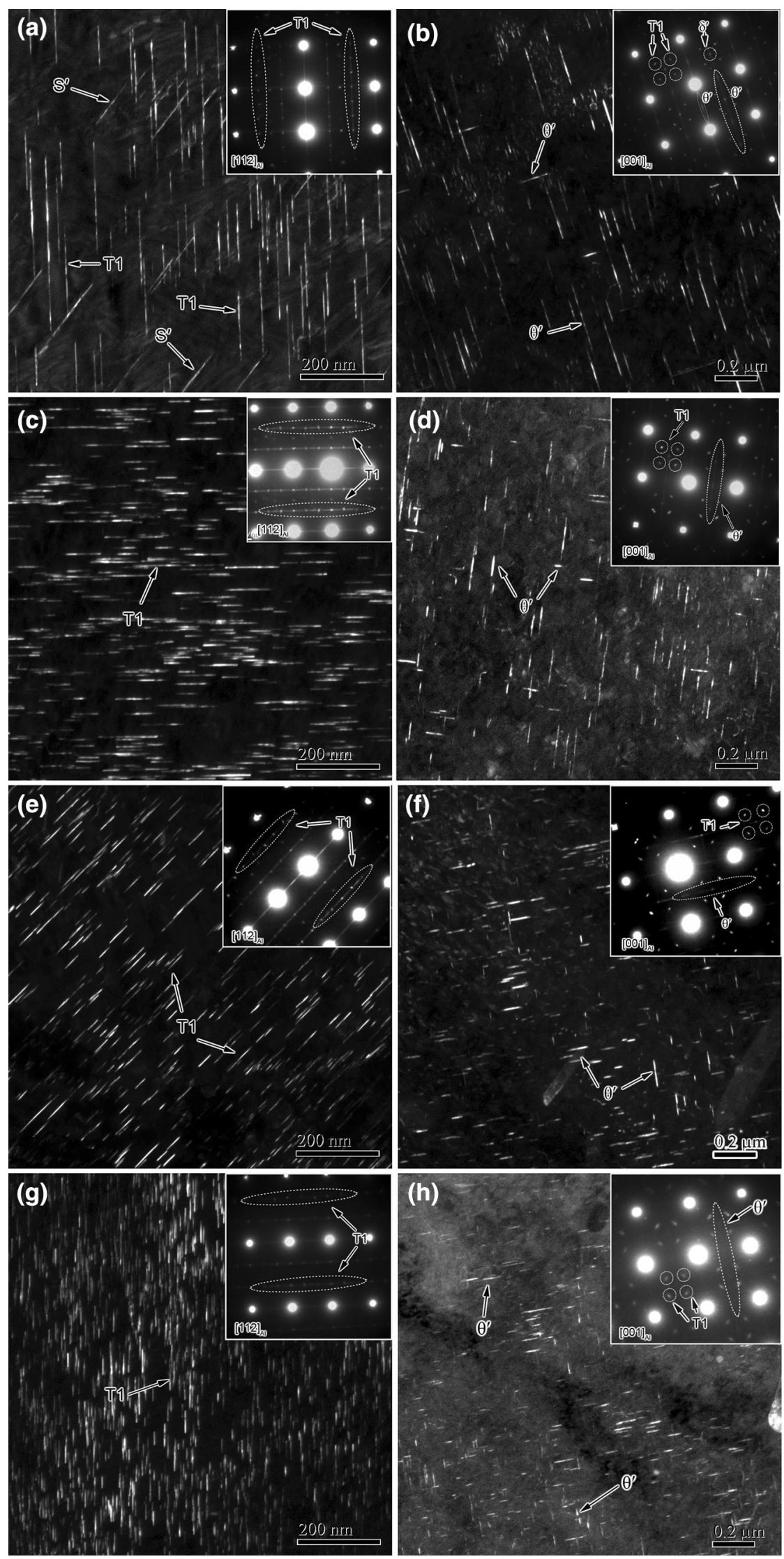
4Fig. 1 SAED patterns and TEM DF images of near peak-aged 2A96 alloys with a, b $0 \%$ (aging for $78 \mathrm{~h}$ ), c, d $3 \%$ (aging for $20 \mathrm{~h}$ ), e, f $8 \%$ pre-deformations (aging for $20 \mathrm{~h}$ ), $\mathbf{g}, \mathbf{h} 12.5 \%$ pre-deformations (aging for $20 \mathrm{~h}$ ). a, c, e, g showing T1 precipitates, the direction is parallel to $<112>_{\mathrm{Al}}$. b, d, f, h showing $\theta^{\prime}$ precipitates, the direction is parallel to $<100>_{\mathrm{Al}}$

in the DF image along the $\langle 112\rangle_{\mathrm{Al}}$ direction (Fig. 1e). In the $[100]_{\mathrm{Al}}$ SAED pattern, the spot intensity of $\theta^{\prime}$ precipitates is further decreased and their size is smaller as observed along the $\langle 100\rangle_{\mathrm{Al}}$ direction (Fig. 1f). For the aged sample with $12.5 \%$ pre-deformation, the population density of T1 precipitates is greatly increased (Fig. 1g). Meanwhile, the intensity of $\theta^{\prime}$ spots is so weak that it is difficult to be observed in the $[100]_{\mathrm{Al}}$ SAED pattern, but $\theta^{\prime}$ precipitates with much small size still can be found in the DF image (Fig. 1h).

According to the above observations, it is clear that both $\mathrm{T} 1$ size and $\theta^{\prime}$ size are decreased with increasing pre-deformation. As for the precipitate population density, it is explicit that $\mathrm{T} 1$ population density is increased with predeformation increasing, but $\theta^{\prime}$ population density is not so clear. To accurately investigate the role of pre-deformation in the population density and the size of $\mathrm{T} 1$ and $\theta^{\prime}$ precipitates, their number and size at different pre-deformation are therefore counted through a software. At least three $\mathrm{DF}$ images showing individual $\mathrm{T} 1$ and $\theta^{\prime}$ precipitates are used for accurate counting. The average population density and diameter of $\mathrm{T} 1$ and $\theta^{\prime}$ precipitates are shown in Table 6. It should be emphasized that although the thickness effect of TEM foil is not considered in this method, and the real variation trend in the population density should be reflected by this statistical method, because the average population density is counted from some images at different locations. The statistical results in Table 6 show that both $\mathrm{T} 1$ diameter and $\theta^{\prime}$ diameter are decreased with predeformation. Meanwhile, the plastic deformation prior to aging increases not only $\mathrm{T} 1$ population density but also $\theta^{\prime}$ population density. However, it is more interesting that there exists much more increase in the $\mathrm{T} 1$ population density than that in the $\theta^{\prime}$ population density.

\subsubsection{Alloy}

Figure 2 presents the SAED patterns taken along the $[112]_{\mathrm{Al}}$ and $[100]_{\mathrm{Al}}$ zone axes and TEM DF images of the near peak-aged $2050 \mathrm{Al}-\mathrm{Li}$ alloy with different pre-deformations. According to SAED patterns, there exist two kinds of aging precipitates, T1 and $\theta^{\prime}$ [22-24]. Compared to those in the $\mathrm{T} 8$-aged alloy with $2 \%$ pre-deformation (Fig. 2a, b), the population density of $\mathrm{T} 1$ is obviously increased and its diameter is found to be decreased in the alloy with $5 \%$ pre-deformation (Fig. 2c). The population density of $\theta^{\prime}$ precipitates also seems to increase (Fig. 2d).

As the pre-deformation is further increased to $10 \%$, the population density of $\mathrm{T} 1$ precipitates is further increased with a little reduction in diameter (Fig. 2e). Meanwhile, it is clear that the diameter of $\theta^{\prime}$ precipitates is greatly decreased (Fig. 2f). In addition, it seems to be that their population density is increased. The average population density and diameter of $\theta^{\prime}$ and $\mathrm{T} 1$ precipitates in the 2050 alloy with different pre-deformation are detected from corresponding DF images, as shown in Table 7. With increasing the pre-deformation from $2 \%$ to $5 \%$ and $10 \%$, $\mathrm{T} 1$ population density is increased and its diameter is decreased sequentially. For $\theta^{\prime}$ precipitate, as the pre-deformation increases from $2 \%$ to $5 \%$, its population density is increased to a certain degree and its diameter is deceased a little. As the pre-deformation is further increased to $10 \%$, its population density is observed to keep unchanged, but the diameter is greatly decreased. This statistical result shows that in 2050 alloy, the pre-deformation accelerates not only the nucleation of $\mathrm{T} 1$ precipitates but also $\theta^{\prime}$ precipitates, and the effectiveness for $\mathrm{T} 1$ precipitates is greater than that for $\theta^{\prime}$ precipitates.

\subsubsection{Alloy}

Figures 3 and 4 show the SAED patterns and TEM images of T8-aged 1460 Al-Li alloy with different pre-deformation. In the $[100]_{\mathrm{Al}} \mathrm{SAED}$ pattern of the alloy aged after $2 \%$ pre-deformation, in addition to the spots of the matrix,

Table 6 Average population density and diameter of $\theta^{\prime}$ and T1 precipitates in near peak-aged 2A96 alloy with different pre-deformation

\begin{tabular}{|c|c|c|c|c|}
\hline Precipitate type & Statistical source & Pre-deformation $(\%)$ & Number density $\left(\# / \mu \mathrm{m}^{2}\right)$ & Diameter $(\mathrm{nm})$ \\
\hline \multirow[t]{4}{*}{$\theta^{\prime}$} & \multirow[t]{4}{*}{ DF images along $\langle 100\rangle_{\mathrm{Al}}$ direction } & 0 & 56.6 & $75-429$ \\
\hline & & 3 & 92.6 & $52-227$ \\
\hline & & 8 & 152.9 & $22-132$ \\
\hline & & 12.5 & 288.8 & $17-85$ \\
\hline \multirow[t]{4}{*}{$\mathrm{T} 1$} & \multirow[t]{4}{*}{ DF images along $<112>_{\mathrm{Al}}$ direction } & 0 & 102.4 & $91-356$ \\
\hline & & 3 & 365.4 & $22-173$ \\
\hline & & 8 & 518.6 & $17-102$ \\
\hline & & 12.5 & 1550.1 & $16-71$ \\
\hline
\end{tabular}



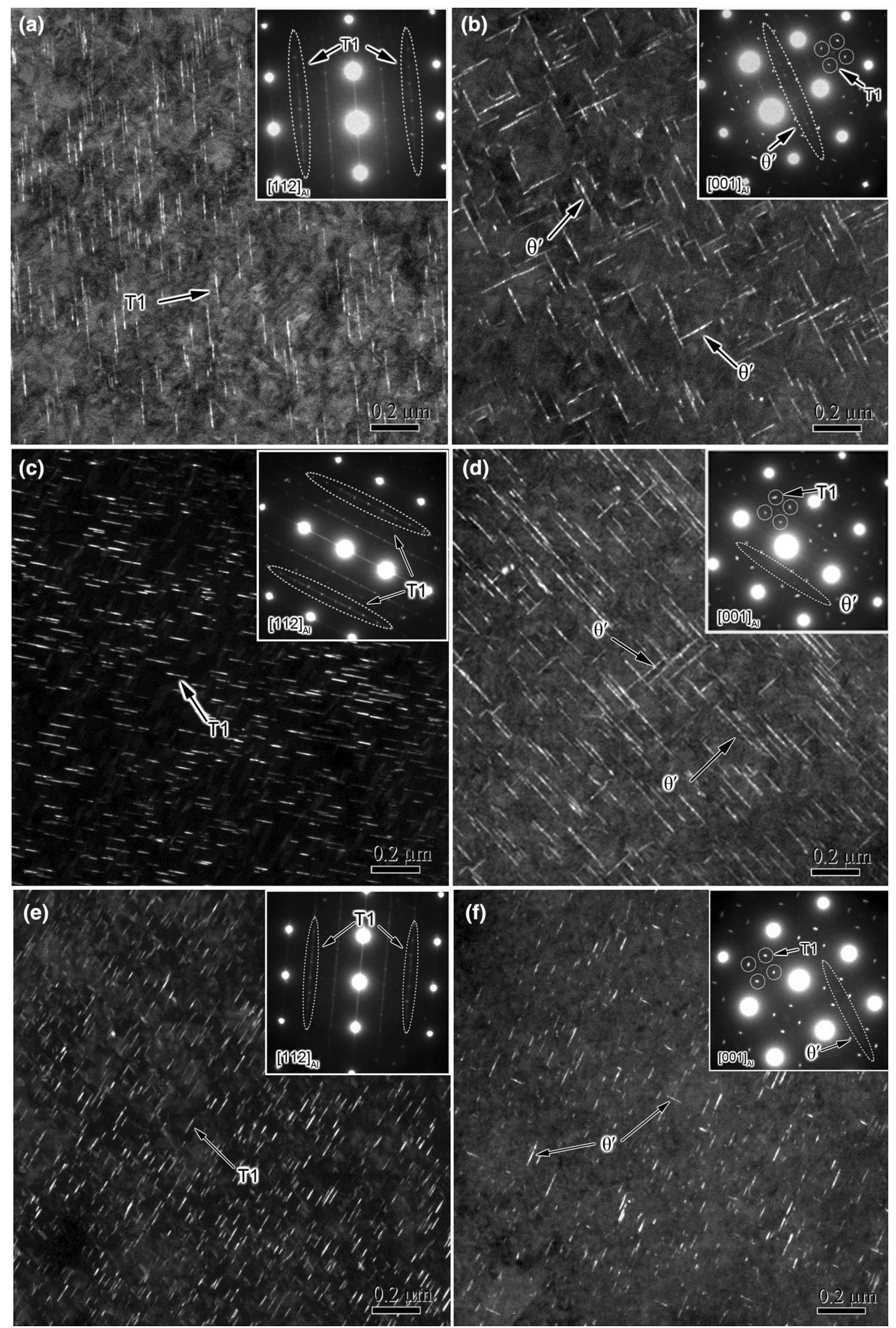
4Fig. 2 SAED patterns and TEM DF images of near peak-aged 2050 alloys with a, b $2 \%$, c, d $5 \%$, e, f $10 \%$ pre-deformations. a, c, e showing $\mathrm{T} 1$ precipitates, the direction is parallel to $\langle 112\rangle_{\mathrm{Al}} \cdot \mathbf{b}, \mathbf{d}$, f showing $\theta^{\prime}$ precipitates, the direction is parallel to $\left\langle 100>_{\mathrm{Al}}\right.$

the main spots are those of $\delta^{\prime}$ (white dotted circle). Meanwhile, the continuous electron diffraction streaks (white dotted ellipse) in the $[100]_{\mathrm{Al}}$ SAED pattern indicate that GP-I zones are formed [23]. There maybe exist some $\theta^{\prime \prime}$ and $\theta^{\prime}$ precipitates, but they cannot be distinguished in the $[100]_{\mathrm{Al}}$ SAED pattern when a large number of GP-I zones exist. These precipitates are therefore annotated as GP-I $\left(\theta^{\prime \prime} / \theta^{\prime}\right)$. Accordingly, a large number of $\delta^{\prime}$ precipitates and considerable GP-I $\left(\theta^{\prime \prime} / \theta^{\prime}\right)$ precipitates are observed in the DF image taken along the $\langle 100\rangle_{\mathrm{Al}}$ direction (Fig. 3a), and GP-I $\left(\theta^{\prime \prime}\right)$ precipitates are flanked by a pair of lenticular $\delta^{\prime}$ precipitates (Fig. 3b). In addition, weak spots of $\mathrm{T} 1$ precipitates in the [112] $]_{\mathrm{Al}}$ SAED pattern are also found and a small number of $\mathrm{T} 1$ precipitates are observed in the bright field (BF) TEM image taken along the $\left\langle 112>_{\mathrm{Al}}\right.$ direction (Fig. 3c).

As the pre-deformation is increased to $4 \%$, the spots of $\delta^{\prime}$ and streaks of GP-I $\left(\theta^{\prime \prime} / \theta^{\prime}\right)$ are still clearly observed in the $[100]_{\mathrm{Al}}$ SAED pattern, a large number of $\delta^{\prime}$ precipitates and considerable GP-I $\left(\theta^{\prime \prime} / \theta^{\prime}\right)$ precipitates are observed in the DF TEM image taken along the $\langle 100\rangle_{\mathrm{Al}}$ direction (Fig. 3d, e). Meanwhile, the spot intensity of T1 precipitates in the $[112]_{\mathrm{Al}}$ SAED pattern is enhanced, and a little more $\mathrm{T} 1$ precipitates are found in the BF TEM image taken along the $\langle 112\rangle_{\mathrm{Al}}$ direction (Fig. 3f).

As the pre-deformation is further increased to $6 \%$, the feature of GP-I zones (white dotted ellipse) in $[100]_{\mathrm{Al}}$ SAED pattern (Fig. 4a) is still evident. A large number of $\delta^{\prime}$ precipitates and considerable GP-I $\left(\theta^{\prime \prime} / \theta^{\prime}\right)$ are therefore observed in the centered DF TEM image taken along the $<100>_{\mathrm{Al}}$ direction (Fig. 4a, b). In addition, the spots of T1 precipitates are observed not only in the $[100]_{\mathrm{Al}}$ SAED pattern (white dotted circle in Fig. 4a) but also in the $[112]_{\mathrm{A} 1}$ SAED pattern (Fig. 4c). Accordingly, more T1 precipitates are observed in the centered DF TEM image taken along the $\langle 112\rangle_{\mathrm{Al}}$ direction (Fig. $4 \mathrm{c}$ ).

At $8 \%$ pre-deformation, the streaks in $[100]_{\mathrm{Al}}$ SAED pattern break up (Fig. 4d), which indicates that the GP-I zones almost disappear and $\theta^{\prime \prime}$ (maybe include $\theta^{\prime}$ ) precipitates form [23]. Therefore, the aging precipitates include a large number of $\delta^{\prime}$, considerable $\theta^{\prime \prime} / \theta^{\prime}$ and some T1, as shown in Fig. $4 d-f$. In addition, it is explicit that the population density of $\mathrm{T} 1$ precipitates is increased (Fig. 4f).

To clearly show the variation of GP-I zones and $\theta^{\prime \prime} / \theta^{\prime}$ precipitates with the pre-deformation, the BF TEM images showing the GP-I zones and $\theta^{\prime \prime} / \theta^{\prime}$ precipitates taken along the $\langle 100\rangle_{\mathrm{Al}}$ direction are recorded, as shown in Fig. 5. According to these BF images showing GP-I zones and $\theta^{\prime \prime} /$ $\theta^{\prime}$ precipitates and those DF images showing T1 precipitates taken along the $\langle 112\rangle_{\mathrm{Al}}$ direction, the number and diameter of GP-I $+\theta^{\prime \prime} / \theta^{\prime}$ and T1 precipitates at different pre-deformations are detected. Because it is difficult to distinguish GP-I zones from $\theta^{\prime \prime}$ precipitates in the BF TEM images, they are collected together. The statistical results are shown in Table 8.

According to this statistical result, $\mathrm{T} 1$ population density is increased sequentially with the pre-deformation, and as the pre-deformation is increased to $8 \%$ from $6 \%$, and there exists a "jump." In addition, their diameter does not display obvious change as the pre-deformation is increased from $2 \%$ to $8 \%$.

For the GP-I $+\theta^{\prime \prime} / \theta^{\prime}$ precipitates, at $2 \%-6 \%$ pre-deformation, there is almost no variation in the population density. As the pre-deformation is further increased to $8 \%$, the GP-I zones almost disappear, and the population density of $\theta^{\prime \prime} / \theta^{\prime}$ precipitates is evidently increased. Furthermore, at $6 \%$ and $8 \%$ pre-deformation, their maximum diameter is a little increased.

\section{Discussion}

\subsection{Effect of Pre-deformation on T1 and $\theta^{\prime}$ Precipitates}

According to the above observations, the microstructure evolutions with pre-deformation are as follows. (1) The pre-deformation not only increases the nucleation rate of T1 precipitates, but also $\theta^{\prime}$ precipitates, especially for $2 \mathrm{~A} 96$ and 2050 alloys. (2) The diameter of individual T1 precipitates and $\theta^{\prime}$ precipitates is decreased due to the

Table 7 Average population density and diameter of $\theta^{\prime}$ and T1 precipitates in near peak-aged 2050 alloy with different pre-deformation

\begin{tabular}{llccc}
\hline Precipitate type & Statistical source & Pre-deformation $(\%)$ & Number density $\left(\# / \mu m^{2}\right)$ & Diameter $(\mathrm{nm})$ \\
\hline$\theta^{\prime}$ & DF images along $<100>_{\mathrm{Al}}$ direction & 2 & 72.4 & $90-330$ \\
& & 5 & 103.5 & $75-260$ \\
& & 10 & 110.5 & $20-80$ \\
$\mathrm{~T} 1$ & DF images along $<112>_{\mathrm{Al}}$ direction & 2 & 76.1 & $85-170$ \\
& & 5 & 192.1 & $40-135$ \\
& & 10 & 260.7 & $20-80$ \\
\hline
\end{tabular}



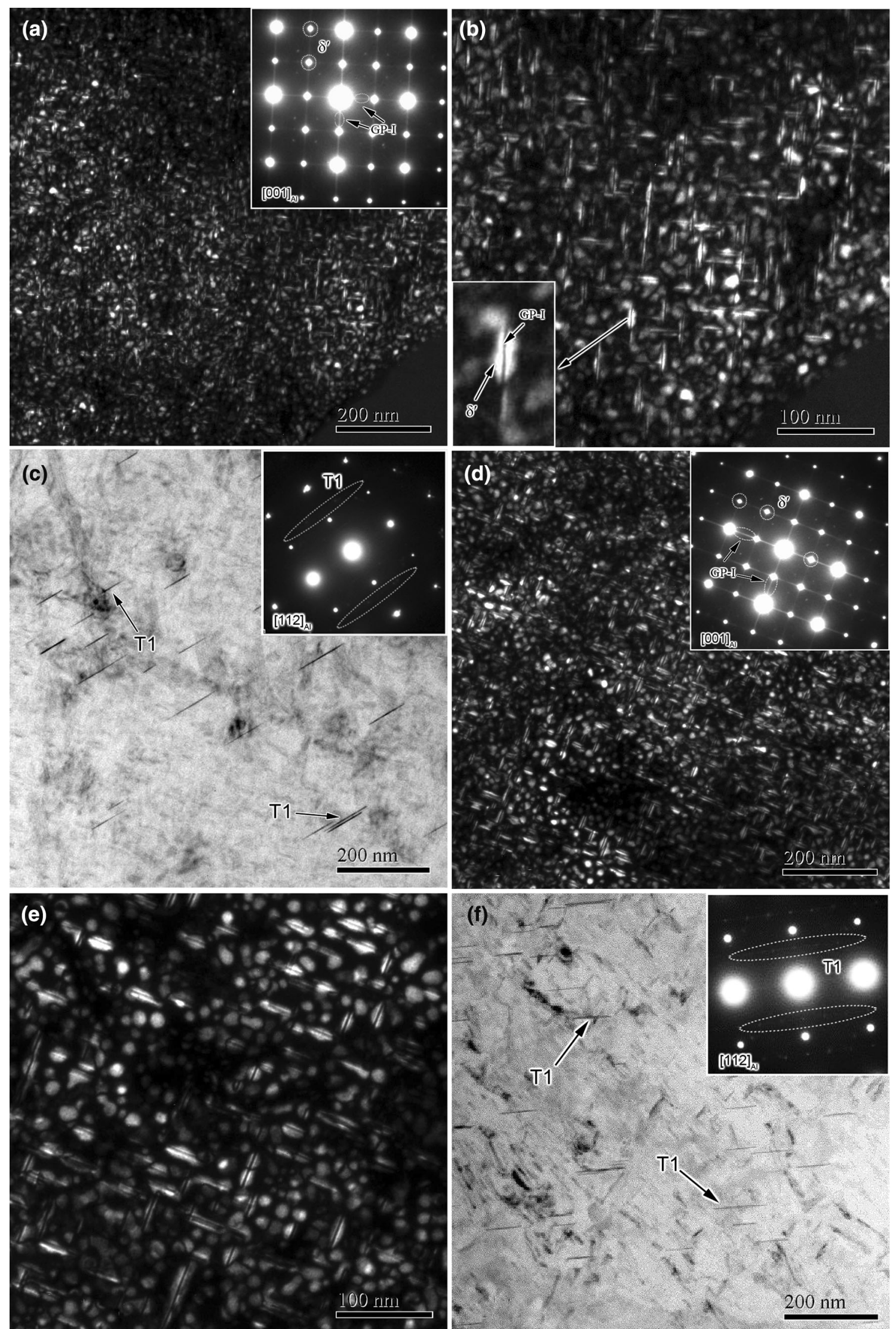
4Fig. 3 SAED patterns and TEM images of T8-aged 1460 alloy with a, b, c $2 \%$, d, e, f $4 \%$ pre-deformation. a, b, d, e TEM DF images showing $\delta^{\prime}$ and GP-I $\left(\theta^{\prime \prime} / \theta^{\prime}\right)$ precipitates, the direction is parallel to $<100>_{\mathrm{Al}}$. c, f TEM BF images showing T1 precipitates, the direction is parallel to $\langle 112\rangle_{\mathrm{Al}}$

introduction of pre-deformation. (3) The higher pre-deformation, the greater the effect. (4) It is more effective for $\mathrm{T} 1$ precipitates than that for $\theta^{\prime} / \theta^{\prime \prime}$ precipitates.

The effect of pre-deformation on the precipitates is associated with the nucleation rate variation. It is known that during solid state transformation, it is necessary to overcome the energy barrier for nucleation. For a given local super-saturation at a given site, the energy barrier is dependent on the misfit strain energy and interfacial energy. $\theta^{\prime \prime}$ precipitates are coherent with Al matrix, which possesses little interfacial energy but a certain misfit strain energy. $\theta^{\prime}$ and $\mathrm{T} 1$ precipitates are semi-coherent with $\mathrm{Al}$ matrix, which not only possesses interfacial energy but also a certain misfit strain energy. To overcome or minimize the resistance or energy barrier, $\theta^{\prime} / \theta^{\prime \prime}$ and $\mathrm{T} 1$ precipitates prefer to nucleate at the sites of dislocation, interface with low-angle grain boundary, stacking fault and vacancy cluster. Therefore, the dislocations introduced by pre-deformation increase the nucleation rate of $\theta^{\prime} / \theta^{\prime \prime}$ and $\mathrm{T} 1$ precipitates.

However, the pre-deformation is more effective on T1 precipitates than that on $\theta^{\prime}$ precipitates, which should be associated with different energy barrier for the nucleation of $\mathrm{T} 1$ and $\theta^{\prime} / \theta^{\prime \prime}$ precipitates. For heterogeneous nucleation on dislocations, assuming an elastic model of a dislocation and an incoherent precipitate, Cahn proposed a dimensionless parameter $\alpha$ to expresses the effectiveness of dislocations on nucleation [25],

$\alpha=\Delta G_{\mathrm{v}} \mu b^{2} / 2 \pi^{2} \sigma^{2}$

where $\Delta G_{\mathrm{v}}$ is the change in volume-free energy, $\mu$ is the shear modulus, $b$ is the Burgers vector and $\sigma$ is the interfacial energy required to form a new surface. The effectiveness of a dislocation in catalyzing nucleation increases as $\alpha$ increases. That is to say, as $\Delta G_{\mathrm{v}}$ and the magnitude of the Burgers vector increase or the surface energy decreases, the effectiveness is increased.

The interfacial energies for the $\theta^{\prime \prime}, \theta^{\prime}$ and $\mathrm{T} 1$ precipitates are $0.05, \quad 0.179$ and $0.13-0.23 \mathrm{~J} / \mathrm{m}^{2}$, respectively $[12,26,27]$. The interfacial energies of $\theta^{\prime}$ and $\mathrm{T} 1$ precipitates are similar. But the change in volume-free energy $\left(\Delta G_{\mathrm{v}}\right)$ associated with the precipitation of T1 may be larger than that associated with $\theta^{\prime}$ since $\mathrm{T} 1$ is an equilibrium phase and $\theta^{\prime}$ is a meta-stable phase.

It was reported that the volumetric strain caused by $\mathrm{T} 1$ precipitates was much higher than that associated with $\theta^{\prime}$ precipitates [12]. In addition, the shear strain, although very similar, lies on different planes and along different direction. The shear strain associated with $\theta^{\prime}$ has a magnitude of 0.333 on the $\{001\}_{\mathrm{Al}}$ plane in the $[100]_{\mathrm{Al}}$ direction, while the shear strain associated with $\mathrm{T} 1$ has a magnitude of 0.354 on the $\{111\}_{\mathrm{Al}}$ plane in the $[112]_{\mathrm{Al}}$ direction [12]. Since the volume strain energy is substantially smaller than the shear strain energy, the manner in which the shear strain associated with the precipitate formation is accommodated may be the key factor in controlling nucleation behavior [12]. Because the shear strain for $\mathrm{T} 1$ is in the plane of the Burgers vector of dislocations in the aluminum matrix, i.e., $\{111\}$ planes, dislocations may thus have a greater effect on $\mathrm{T} 1$ nucleation than that on $\theta^{\prime}$ nucleation.

The above two factors, i.e., the larger $\Delta G_{\mathrm{v}}$ and the $\{111\}$ shear strain aid in the preferential nucleation of $\mathrm{T} 1$ precipitates on dislocations over that of $\theta^{\prime}$ precipitates. This explains the greater effect of pre-deformation on T1 population density than on $\theta^{\prime}$ population density. Afterward, an increase in $\mathrm{T} 1$ population density creates overlapping diffusion fields as $\mathrm{T} 1$ precipitate grows, causing its average diameter to decrease. The refinement of the precipitate microstructure combined with the overlapping diffusion fields corresponds to the enhanced kinetics due to the increased population density of strengthening precipitates and the shorter diffusion time of solute atoms during precipitate growth, which therefore accelerates the aging response of $\mathrm{Al}-\mathrm{Cu}-\mathrm{Li}$ alloys. Meanwhile, the growth of $\mathrm{T} 1$ precipitates rapidly consumes $\mathrm{Cu}$ atoms in the matrix, which deters the growth of $\theta^{\prime}$ precipitates and leads to their refinement.

Among the precipitates of $\mathrm{T} 1, \theta^{\prime}$ and $\delta^{\prime}$ in $\mathrm{Al}-\mathrm{Cu}-\mathrm{Li}$ alloys, $\mathrm{T} 1$ precipitate has a hexagonal crystal structure and a platelet morphology with a main orientation relationship of $\{0001\}_{\mathrm{T} 1} / /\{111\}_{\mathrm{Al}}$ and $<1010>_{\mathrm{T} 1} / /<110>_{\mathrm{Al}}[28,29]$. So $\mathrm{T} 1$ precipitates generate a great impediment to the dislocation glide along the $\{111\}_{\mathrm{Al}}$ plane and therefore contribute to the strongest strengthening effect, compared to other precipitates like $\theta^{\prime}$ and $\delta^{\prime}$. The pre-deformation consequently enhances the $\mathrm{Al}-\mathrm{Cu}-\mathrm{Li}$ alloy strength by through increasing the $\mathrm{T} 1$ population density.

\subsection{Effect of Pre-deformation Associated with Composition}

According to the above observations, it is also found that the pre-deformation effectiveness is dependent on alloy's composition. Figure 6 shows the population density of T1 and $\theta^{\prime}$ in 2A96 and 2050 alloys. For the 2A96 alloy, as the pre-deformation is increased to $12.5 \%$, the population density of $\mathrm{T} 1$ is increased by seven times more than that of $\theta^{\prime}$. However, for the 2050 alloy, the population density of $\mathrm{T} 1$ is increased about two times more than that of $\theta^{\prime}$ as the 

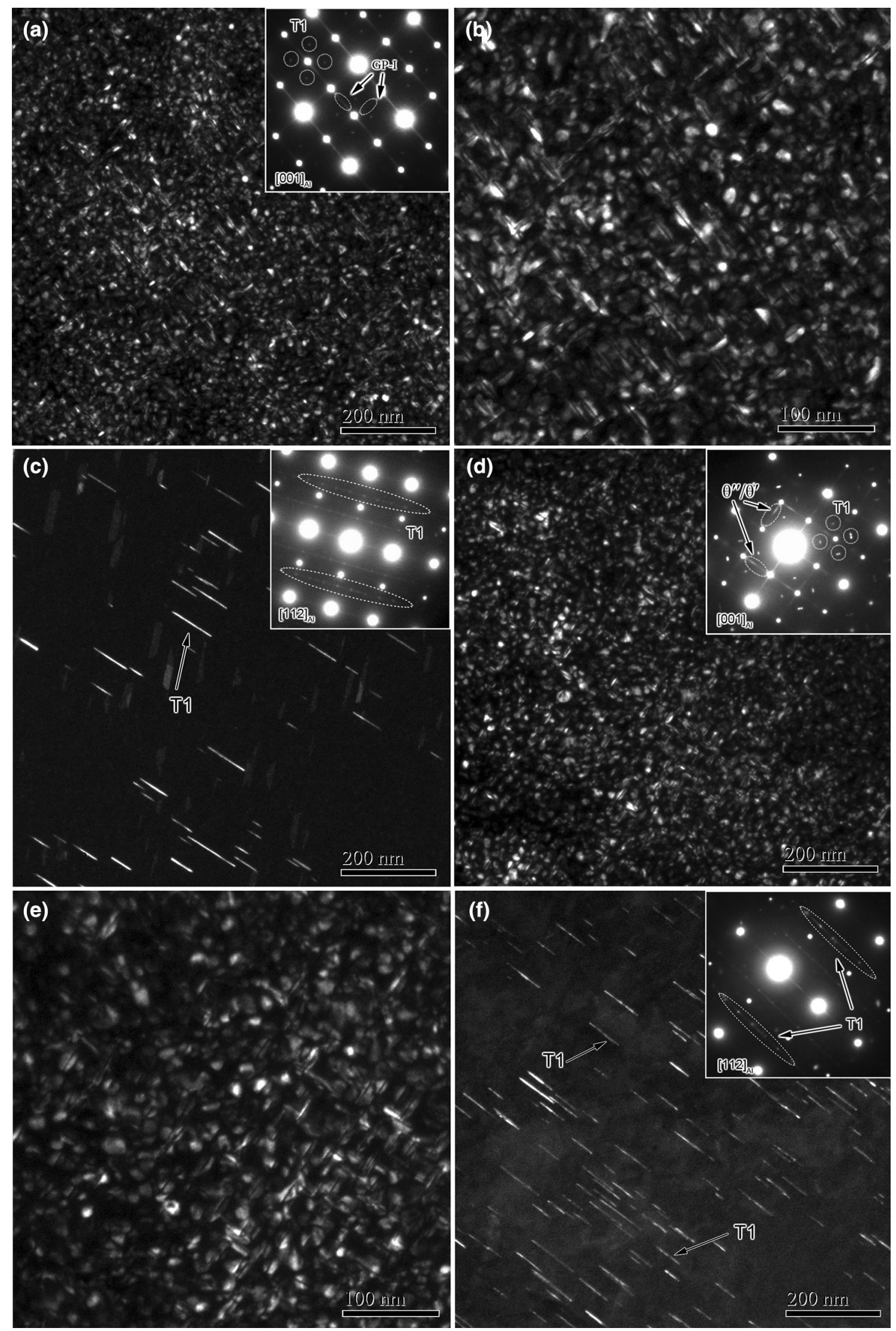
4Fig. 4 SAED patterns and TEM DF images of T8-aged 1460 alloy with a, b, c $6 \%, \mathbf{d}, \mathbf{e}, \mathbf{f} 8 \%$ pre-deformation. a, b, d, e showing $\delta^{\prime}$ and $\mathrm{GP}-\mathrm{I}\left(\theta^{\prime \prime} / \theta^{\prime}\right)$ precipitates, the direction is parallel to $\left\langle 100>_{\mathrm{Al}}\right.$. c, f showing $\mathrm{T} 1$ precipitates, the direction is parallel to $\langle 112\rangle_{\mathrm{Al}}$

pre-deformation is increased to $10 \%$. In 1460 alloy, although the pre-deformation improves $\mathrm{T} 1$ population density, the effectiveness is much smaller than that in 2A96 and even 2050 alloys. Meanwhile, $\theta^{\prime \prime} / \theta^{\prime}$ precipitation is promoted only at $8 \%$ pre-deformation.

Although there exist different micro-alloying elements in the three $\mathrm{Al}-\mathrm{Cu}-\mathrm{Li}$ alloys, the main difference is the $\mathrm{Cu}$ and $\mathrm{Li}$ concentrations and their ratio. It is known that the thermodynamic driving force for the preferential precipitation is a function of the relative saturation of the matrix, or the $\mathrm{Cu} / \mathrm{Li}$ ratio. This ratio may indicate a significant chemical driving force for the precipitation of either $\mathrm{T} 1, \theta^{\prime}$ or $\delta^{\prime}$. In the $\mathrm{Al}-\mathrm{Cu}-\mathrm{Li}$ alloy with a high $\mathrm{Cu} / \mathrm{Li}$ ratio (or low $\mathrm{Li}$ concentration), the dominant precipitate is $\theta^{\prime}$ or the fraction of $\theta^{\prime}$ is increased; While in that with medium $\mathrm{Cu} /$ $\mathrm{Li}$ ratio, the dominant precipitate is $\mathrm{T} 1$. The chemical driving force for preferential precipitation caused by supersaturation combined with the effectiveness $\alpha$ introduced by dislocations determines the different effectiveness for $\mathrm{T} 1$ nucleation.

Compared to 2050 alloy, 2A96 alloy contains a higher concentration of $\mathrm{Li}(1.28 \%)$ and possesses medium $\mathrm{Cu} / \mathrm{Li}$ ratio (2.97), and therefore possesses a higher thermodynamic driving force for $\mathrm{T} 1$ preferential precipitation from the matrix. Due to higher thermodynamic driving force combined with higher effectiveness of pre-deformation, the population density of $\mathrm{T} 1$ precipitates therefore increases greatly as pre-deformation increases (Fig. 6). However, in 2050 alloy, due to the lower thermodynamic driving force associated with relative lower super-saturation, the increase in $\mathrm{T} 1$ population density is not as high as that in $2 \mathrm{~A} 96$ alloy.

1460 alloy is featured with a high Li concentration (2.14\%) and a low $\mathrm{Cu} / \mathrm{Li}$ ratio (1.46). This composition
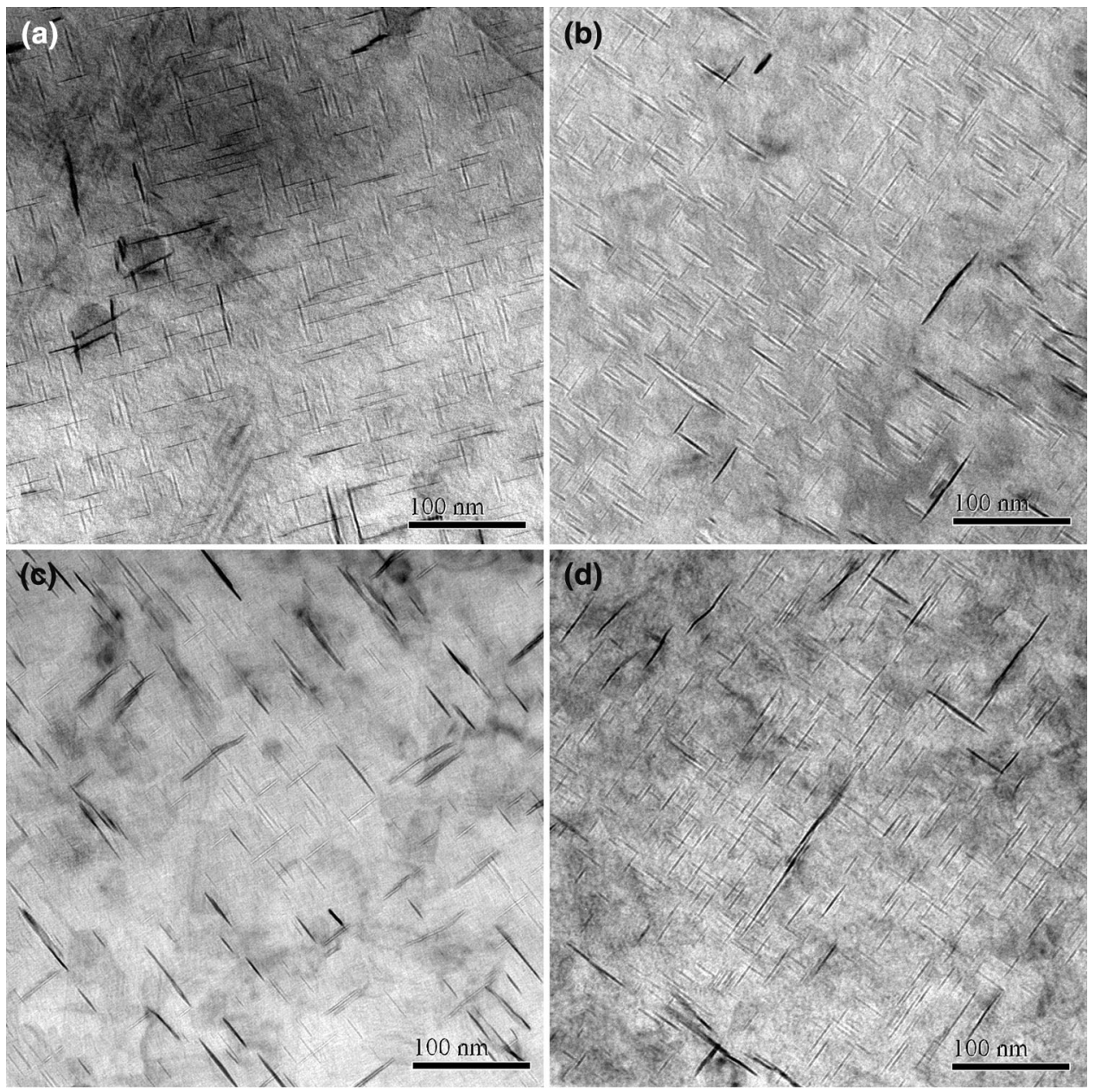

Fig. 5 TEM BF images showing GP-I zones and $\theta^{\prime \prime} / \theta^{\prime}$ precipitates in the T8-aged 1460 alloy with a $2 \%$, b $4 \%$, c $6 \%$, d $8 \%$ pre-deformation. The direction is parallel to $<100>_{\mathrm{Al}}$ 
Table 8 Average population density and diameter of GP-I $+\theta^{\prime \prime} / \theta^{\prime}$ and T1 precipitates in T8-aged 1460 alloy with different pre-deformation

\begin{tabular}{lllll}
\hline Precipitate & Statistical source & Pre-deformation $(\%)$ & Number density $\left(\# / \mu \mathrm{m}^{2}\right)$ & Diameter $(\mathrm{nm})$ \\
\hline GP-I $+\theta^{\prime \prime} / \theta^{\prime}$ & BF images along $<100>_{\mathrm{Al}}$ direction & 2 & 1304 & $19-68$ \\
& & 4 & 1346 & $20-78$ \\
& & 6 & 1476 & $19-124$ \\
& & 8 & 27 & $19-108$ \\
$\mathrm{~T} 1$ & DF images along $<112>_{\mathrm{Al}}$ direction & 2 & 48 & $25-122$ \\
& & 4 & 68 & $25-118$ \\
& 6 & 164 & $23-120$ \\
& 8 & & $15-112$ \\
\hline
\end{tabular}

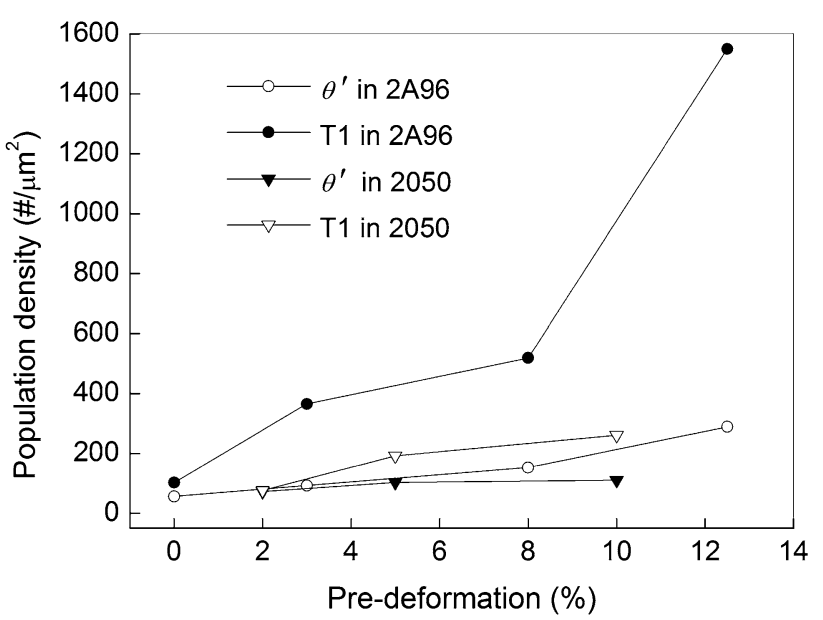

Fig. 6 Population density of $\mathrm{T} 1$ and $\theta^{\prime}$ precipitates in 2A96 and 2050 alloys as a function of pre-deformation

feature determines a much great thermodynamic driving force for $\delta^{\prime}$ preferential precipitation. In addition, $\delta^{\prime}$ precipitates are coherent with the $\mathrm{Al}$ matrix and possess a much small interfacial energy of $0.014 \mathrm{~J} / \mathrm{m}^{2}[12,27]$. No matter pre-deformation is supplied; a large number of $\delta^{\prime}$ precipitates are therefore formed at initial aging stage, as shown in Fig. 7.

Due to the precipitation of $\delta^{\prime}$ with a large volume fraction, it is rational to deduce that $\mathrm{Li}$ concentration in the matrix greatly decreases or the $\mathrm{Cu} / \mathrm{Li}$ ratio increases. Then the high coherency between GP-I zones and the matrix, and a much small interfacial energy of $0.003 \mathrm{~J} / \mathrm{m}^{2}$ at $150{ }^{\circ} \mathrm{C}$ [30], as well as the chemical driving force (composition) favors the formation of GP-I zones at temperatures of $130-160{ }^{\circ} \mathrm{C}$.

$\theta^{\prime \prime}$ precipitates are also coherent with the matrix, but compared to GP-I zones, there exists a little higher interfacial energy of $0.05 \mathrm{~J} / \mathrm{m}^{2}$ [12] between the $\theta^{\prime \prime}$ precipitates and the matrix. The dislocations introduced by pre-deformation should promote their nucleation during aging process. Because of the preferential formation of GP-I zones and $\delta^{\prime}$ precipitates, the effectiveness of promoting $\theta^{\prime \prime}$ precipitation becomes apparent till at $8 \%$ pre-deformation. Accordingly, the streaks of GP-I zones almost disappear in
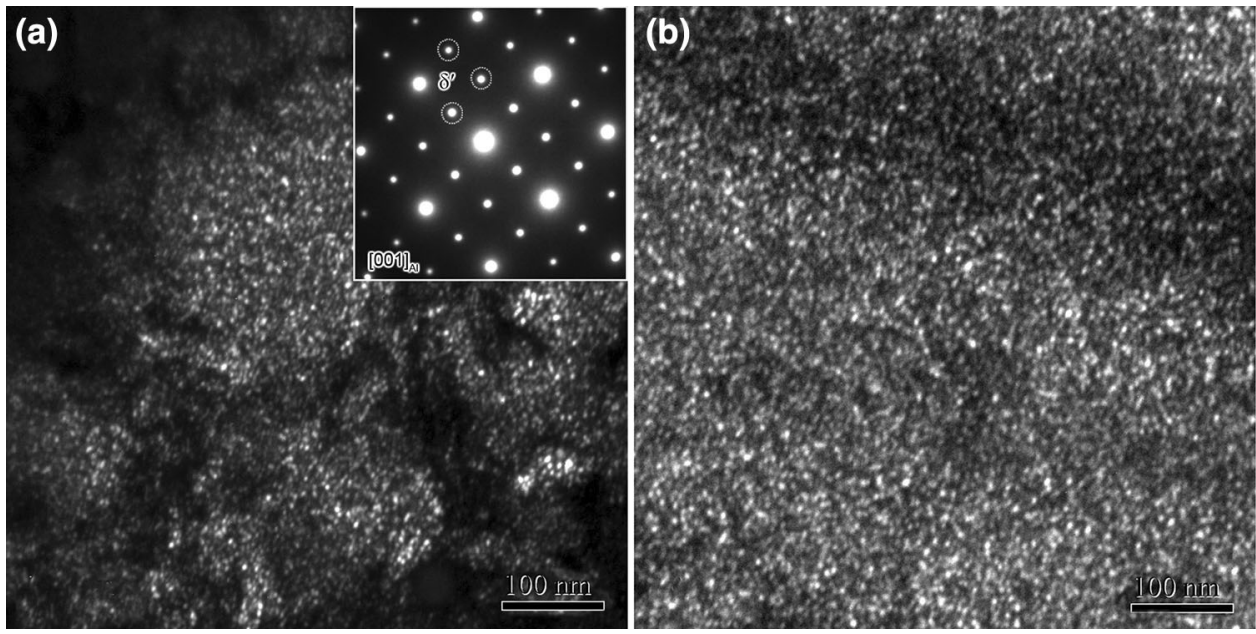

Fig. $7[100]_{\mathrm{Al}}$ SAED pattern and DF TEM images (showing $\delta^{\prime}$ precipitates) of 1460 alloy after a aging at $130{ }^{\circ} \mathrm{C}$ for $4 \mathrm{~h}$ following $4 \%$ predeformation and $\mathbf{b}$ aging at $160{ }^{\circ} \mathrm{C}$ for $0.5 \mathrm{~h}$. The images are taken along the $[100]_{\mathrm{Al}}$ zone axis 
the $[100]_{\mathrm{Al}}$ SAED pattern (Fig. 4d), and the population density of $\theta^{\prime \prime} / \theta^{\prime}$ precipitates is evidently increased (Table 8).

\section{Conclusions}

1. The influence of the pr-deformation on precipitates in $\mathrm{Al}-\mathrm{Cu}-\mathrm{Li}$ alloys is dependent on their $\mathrm{Cu}$ and $\mathrm{Li}$ concentrations and $\mathrm{Cu} / \mathrm{Li}$ ratio.

2. With increasing the pre-deformation, the population density of $\mathrm{T} 1$ precipitates increases in all three $\mathrm{Al}-\mathrm{Cu}-$ $\mathrm{Li}$ alloys, and their diameter decreases in 2050 alloy with a higher $\mathrm{Cu} / \mathrm{Li}$ ratio and $2 \mathrm{~A} 96$ alloy with a medium $\mathrm{Cu} / \mathrm{Li}$ ratio, but the greatest effectiveness is observed in 2A96 alloy.

3. In 2050 and 2 A96 alloys, the pre-deformation increases the population density of $\theta^{\prime}$ precipitates and therefore decreases their diameter, but the effectiveness is smaller compared to that on $\mathrm{T} 1$ precipitates.

4. In 1460 alloy, the main precipitates are $\delta^{\prime}$. At $2 \%-6 \%$ pre-deformation, GP-I zones form, but pre-deformation displays little influence on their formation. Eight percentage pre-deformation promotes $\theta^{\prime \prime} / \theta^{\prime}$ precipitation and increases their population density.

Acknowledgements Authors thank the National High Technology Research and Development Program of China (No. 2013AA032401) and Teacher's Research Foundation of Central South University (No. 2013JSJJ 001) for the financial support. The financial support from Nonferrous Metal Oriented Advanced Structural Materials and Manufacturing Cooperative Innovation Centre was also greatly appreciated.

\section{References}

[1] R.J. Rioja, J. Liu, Metall. Mater. Trans. A 43, 3325 (2012)

[2] T. Dursun, C. Soutis, Mater. Des. 56, 862 (2014)
[3] T.R. Prabhu, Acta Metall. Sin. (Engl. Lett.) 28, 909 (2015)

[4] J.F. Li, Z.W. Peng, C.X. Li, W.J. Chen, Trans. Nonferrous Met. Soc. China 18, 755 (2008)

[5] J.F. Li, N. Birbilis, Z.Q. Jia, B. Cai, Z.Q. Zheng, Mater. Charact. 60, 1334 (2009)

[6] J.T. Jiang, Q.J. Tang, L. Yang, K. Zhang, S.J. Yuan, L. Zhen, J. Mater. Process. Technol. 227, 110 (2016)

[7] R.N. Lumley, I.J. Polmear, A.J. Morton, Mater. Sci. Technol. 19, 1483 (2003)

[8] X.F. Li, K. Lei, P. Song, X.Q. Liu, F. Zhang, J.F. Li, J. Chen, J. Mater. Eng. Perform. 24, 3905 (2015)

[9] H.M. Wang, C.Q. Xia, P. Lei, Z.W. Wang, J. Cent, South Univ. Technol. 18, 1349 (2011)

[10] M. Wang, S.S. Chen, Acta Aeronaut. Astronaut. Sin. 18, 379 (1997). (in Chinese)

[11] X.Y. Wei, Z.Q. Zheng, Z.R. Pan, Y.Y. Chen, S.C. Li, Q.N. Chen, Rare Metal Mater. Eng. 37, 1996 (2008). (in Chinese)

[12] B.M. Gable, A.W. Zhu, A.A. Csontos, E.A. Starker Jr, J. Light Met. 1,1 (2000)

[13] J.D. Kim, J.K. Park, Metall. Trans. A 24, 2613 (1993)

[14] S.P. Ringer, B.C. Muddle, I.J. Polmear, Metall. Mater. Trans. A 26, 1659 (1995)

[15] W.A. Cassada, G.J. Shiflet, E.A. Starker Jr., Metall. Trans. A 22, 287 (1991)

[16] W.A. Cassada, G.J. Shiflet, E.A. Starker Jr., Metall. Trans. A 22, 299 (1991)

[17] A.K. Hopkins, K.V. Jata, R.J. Rioja, Mater. Sci. Forum 217-222, 421 (1996)

[18] Z.S. Yuan, Z. Lu, Y.H. Xie, S.L. Dai, C.S. Liu, Rare Metal Mat. Eng. 36, 493 (2007). (in Chinese)

[19] C. Gao, Y. Luan, J.C. Yu, Y. Ma, Trans. Nonferrous Met. Soc. China 24, 2196 (2014)

[20] B.I. Rodgers, P.B. Prangnell, Acta Mater. 108, 55 (2016)

[21] H.Y. Li, W. Kang, X.C. Lu, J. Alloys Compd. 640, 210 (2015)

[22] N. Gao, M.J. Starink, L. Davin, A. Cerezo, S.C. Wang, P.J. Gregson, Mater. Sci. Technol. 21, 1010 (2005)

[23] S.C. Wang, M.J. Starink, Int. Mater. Rev. 50, 193 (2005)

[24] J.C. Huang, A.J. Ardrell, Mater. Sci. Technol. 3, 176 (1987)

[25] J.W. Cahn, Acta Metall. 5, 169 (1957)

[26] D.Y. Li, L.Q. Chen, Acta Mater. 46, 2573 (1998)

[27] S.F. Baumann, D.B. Williams, Scr. Metall. 18, 611 (1984)

[28] S. Hirosawa, T. Sato, A. Kamio, Mater. Sci. Eng. A 242, 195 (1998)

[29] J.F. Nie, B.C. Muddle, Mater. Sci. Eng. A 319-321, 448 (2001)

[30] L. Loechte, A. Gift, G. Gottstein, I. Hurtado, Acta Mater. 48, 2969 (2000) 